\title{
CARCINOMA OF THE LUNG
}

\section{INTRODUCTORY}

\author{
By MAURICE DAVIDSON, M.A., M.D. Oxon, F.R.C.P. LoND. \\ (Member of the Association of Physicians of Great Britain and Ireland, Physician to the Brompton \\ Hospitai for Consumption and Diseases of the Chest.)
}

The following series of articles by well-known authorities forms a valuable and welcome symposium of modern knowledge relating to a condition which is now recognised as widespread, although most of us can remember a time, not so far distant, when it was regarded as a rarity. An interesting résumé of the historical aspects of lung cancer was published by Huguenin (5) in 1928 , and in view of recent statistics of the incidence of this disease it is worth while to glance at the table given by, this author of some of the earlier figures.

Table

\begin{tabular}{c|c|l}
\hline $\begin{array}{c}\text { Autopsies-Number } \\
\text { of }\end{array}$ & $\begin{array}{c}\text { Pulmonary cancer } \\
\text {-Cases of }\end{array}$ & \multicolumn{1}{c}{ Authors and dates } \\
\hline & 40 & Wolff \\
I r,400 & I1,000 & Fuchs (1854 to I896) \\
7,006 & 6 & Norwiski (Lemberg) (1886 to 1903) \\
16,047 & $6 \mathrm{r}$ & Lavrinovic (Petrograd) (1905 to 1914) \\
\hline
\end{tabular}

Incidence of Pulmonary Cancer (Huguenin, loc. cit.).

Although there has been, and still is, some controversy as to the exact interpretation of modern statistics on the subject, it will now hardly be denied by any who have real knowledge of chest disease that the frequency with which primary bronchial carcinoma is encountered, not only in hospital, but also in private practice, has created a serious problem of practical medicine, Tudor Edwards (4), reviewing the literature in the Medical Annual for I942, quotes the following striking figures: "Bruce and Kenning in a clinical series of 936 cases admitted to a tumour clinic found that only carcinoma of the stomach, uterus (cervix), and breast had a greater incidence than pulmonary cancer. In 7,685 consecutive autopsies Koletsky found carcinoma of the lung second only to carcinoma of the stomach. Olsen, reporting cases of carcinoma of the lung from the Boston City Hospital, found that the incidence increased annually from $7 \cdot 5$ per cent. of all carcinomas in 1929 to $19 \cdot 1$ per cent.in I934. Matz from the Veterans' Bureau Hospital found that in autopsies the incidence of pulmonary cancer increased from $6 \cdot 4$ per cent. of all cancers in the years $1927-31$ to $15 \cdot 8$ per cent. for the years $1932-37$, being as high as $23 \cdot 4$ per cent. for I937."

The above facts provide abundant justification for the gradual change of outlook of the up-to-date practitioner, who, having started with the conception of malignant disease of the respiratory tract as a rarity, is now compelled to regard it as distressingly common. In spite of this, however, and of the steady improvement in our diagnostic technique, it still remains true that prompt systematic examination of what should be regarded as suspicious cases is the exception rather than the rule, even in large centres where every facility for complete investigation by modern methods is within the reach of the practitioner. Roberts (6) only recently observed that " the great majority of these cases are already incurable by the time the diagnosis is made . . . yet a considerable percentage have been under medical observation for months before the diagnosis is completed" (my italics). This, unfortunately, is still the case, and, in the face of all that has been written and taught on the subject in the last few years, is something of a reproach to many in the medical profession who should be in a position to know better.

An interesting comparison may, perhaps, legitimately be drawn between lung cancer and pulmonary tuberculosis, since between these two conditions, so far as early diagnosis goes, one can see some sort of analogy. Those whose work involves study of large numbers of cases of tuberculosis of the lungs in the young adult period are well aware that the active spreading 
granuloma in its early stages is more often than not entirely symptomless, and recognisable only by radiology. This conception of adult phthisis has been gradually but surely gaining ground, and the growing enthusiasm for mass miniature radiography is the latest testimony to its truth. Early diagnosis of bronchial carcinoma, which is equally if not more imperative if successful therapy is to follow, has not so far met with a similar success, nor is it so generally understood that lung cancer in the operable stages is also a symptomless disease, so far as the average patient is concerned. This is, perhaps, largely due to the fact that even present-day articles and text-books, especially the latter, tend to concentrate on descriptions, both clinical and radiological, of the disease when it has reached a stage far beyond the scope of radical surgical treatment. It may also be said, not without justice, that the average practitioner is unaware of the possibilities of the modern operation of pneumonectomy, from which he is inclined to shrink, no less than the patient, especially when the latter's symptoms are so slight as to constitute at most an inconvenience rather than a serious disability.

In a discussion on intrathoracic tumours only four years ago (1) I urged that " if we are to make any real headway in the treatment of these malignant growths we must envisage a much more uniform and regular system of complete investigation of the patient at a stage when symptoms are minimal, and when the results of clinical examination and even of straightforward X-ray examination may be indefinite or perhaps entirely negative." I am strongly inclined to the view that the presence of gross abnormal physical signs in a patient with lung cancer is practically always indicative of an advanced condition for which only palliative treatment is possible. I would go so far as to say that a similar principle applies in a considerable number of cases in which, apart from the physical signs in the chest, a straight $\mathrm{X}$-ray shows abnormal shadows of considerable extent so that they are easily recognisable even by those whose experience of chest radiograms is limited. It is well known that the appearances seen in many typical X-ray pictures of lung cancer are due not to the actual mass of primary growth, which may be comparatively small, but to the collapsed condition of the lung which results from obstruction of a main bronchus or one of its primary divisions by a tumour. "Even in inoperable cases it happens not infrequently that the patient shows no gross clinical evidence of disease until bronchial obstruction, partial or complete, has occurred, and evidence of such obstruction is often a comparatively late phenomenon, seen only when extensive spread of the growth has already taken place" (Davidson (3) ). It is not, perhaps, generally recognised that partial collapse of a lobe may be legitimately inferred in a radiogram in which there is no obvious visceral displacement, and which does not even show a homogeneous opacity of the type commonly associated with an area of lung which has been rendered airless. I have, moreover, had occasion to point out (2) that " the diminution in size of a lobe which results from obstructive collapse may lead to localised compensatory emphysema, and that this may be recognisable in the X-ray film as the only detail which gives a clue to pulmonary collapse."

I have laid stress on the above points in order to try to give some lead as to the considerations that should pass through the mind of any observer who is determined to seek and to find the earliest evidences of lung cancer, and who in pursuance of this object must, among other things, have become what one American author has aptly described as " atelectasisconscious." "It is, moreover, necessary to add a warning as to the danger of that much-abused expression " unresolved pneumonia," a phrase which is employed only too often to cover a failure on the part of the clinician to recognise the true underlying pathology of some obscure pulmonary condition which he has assumed to be inflammatory in origin, but which is in reality due to secondary phenomena following the development of a neoplasm within the chest. This error, for which I feel there is much less excuse nowadays than formerly, should always be remembered in connection with the problem of differential diagnosis of obscure chest conditions, among which the possibility of new growth must always be reckoned with, especially in patients of advanced middle-age, that is to say, in the region of fifty or thereabouts. McGibbon, Baker-Bates, and Mather (7) have called attention to this in an extremely interesting series of thirty-eight patients in whom a diagnosis of unresolved pneumonia had been made and who were subsequently examined by them with the bronchoscope. Of all these, 8 were found to be suffering from bronchial carcinoma, I from an extra bronchial tumour of unknown pathology, 2 from impacted non-radio-opaque foreign body, 5 from bronchiectasis, I from inflammatory bronchial stenosis, 2 from lung abscess, I from enlarged bronchial glands, and 18 (children) from varying degrees of incomplete bronchial obstruction, apparently caused by secretion.

The differential diagnosis of bronchial carcinoma is a subject on which it is extremely diffi- 
cult to speak with precision, except perhaps in those advanced cases in which, owing to extension of the growth sufficient to cause anatomical changes in the lung or elsewhere, the clinical and radiological pictures are so characteristic as to be almost unmistakable. In these circumstances there is not likely to be much difficulty, at least to the experienced observer. In the really early cases, of which, as I have already indicated, it is not possible to show a picture that is in any way pathognomonic, the diagnosis is practically always a matter of elaborate investigation (in which expert bronchoscopic examination plays an extremely important part) of a patient whose symptoms are suggestive of some organic lesion of the respiratory tract, and in whom the commoner conditions such as pulmonary tuberculosis or non-tuberculous bronchiectasis have been satisfactorily excluded and the observer is still anxious as to the existence of serious organic trouble. Not a few early cases of bronchial carcinoma manifest themselves in the first instance by a slight haemoptysis. Apart from the principle that no such case should ever be dismissed lightly because of the absence of physical signs of disease (and even nowadays it is still unfortunately necessary to labour this point with an insistence which ought to be needless), it must be remembered that even a good radiogram may fail to show any positive evidence of organic disease. The age of the patient is a matter of importance, and though a certain proportion of cases of lung cancer do occur in young subjects, the average example is seen in patients round about the age of fifty. It is a generally useful dictum that while haemoptysis in a young subject is more likely to be indicative of tubercle, the occurrence of bleeding from the respiratory passages in the middle-aged or elderly should always raise a serious suspicion of carcinoma, and the patient should not be denied the opportunity of bronchoscopy. The adventitious shadows in a radiogram showing partial or patchy collapse in association with growth are sometimes difficult to distinguish with certainty from those due to tuberculous infiltration of the lung parenchyma, and the distinction between the two conditions may tax the ability of even the most experienced chest radiologists. Often the latter can say no more than that the appearances are not entirely characteristic of tubercle, and if in such circumstances the sputum has been persistently T.B. negative, a diagnosis of carcinoma must never be ruled out until bronchoscopy has been thoroughly exploited, possibly on more than one occasion. Disproportion between the patient's consciousness of dysfunction (especially in respect of dyspnoea), and objective evidence of disease should always be regarded as a possible indication for complete investigation of the respiratory tract, and while a certain sanity of outlook must obviously be preserved in deciding whether to submit an apparently healthy patient to the inconvenience and unpleasantness of a bronchoscopic examination, there can be no excuse for failure to insist on this in cases in which the clinician is unable to rid his mind of the suspicion that he may be dealing with an early bronchial growth. More than this I do not think it is possible to say, and I have to admit that the reasonableness of such suspicion is mainly a matter of experience of a sufficient number of cases and the possession of a certain clinical instinct that is the corollary of such experience.

The treatment of these cases has been dealt with at length in the following articles. I would only say by way of introduction that the results of good team-work in thoracic surgery have shown ample justification for the hope and faith expressed by those of us who have been chiefly concerned with this branch of therapeutics. For the inoperable case there is undoubtedly much that can be done to palliate the more distressing features that often characterise the last few weeks or months of life in these unfortunate patients. It still remains, in a large number of cases, for the family practitioner to play his part, perhaps the most important of all, in the selection of cases at a stage when full investigation is likely to be fruitful of useful results. In the words of that distinguished teacher, Sir Arthur Hall, " Forewarned is forearmed; If the practitioner is aware of the varied and insidious disguises which early pulmonary cancer may assume, and if he knows what steps must be taken to unmask them, it rests with him, by acting upon such knowledge, to help more than anyone else in forwarding advance in the treatment of this grave disorder."

\section{REFERENCES}

(I) DAVIDSON, M., Proc. Roy. Soc. Med., 1939, 32, 1342.

(2) DAVIDSON, M., Ibid., I939, 32, 1345.

3) DAVIDSON, M., Med. Press and Circ., 1940, 203, 345.

(4) EDWARDS, A. T., Med. Anmual, 1942, p. 226. Bristol: John Wright \& Sons.

5) HUGUENIN, R., " Cancer primitif du Poumon." Paris, 1928, Masson et Cie.

6) ROBERTS, J. E. H., Med. Press and Circ., 1940, 203, 88-91.

(7) McGIBBON, J. E. BAKER-BATES, E. J., and MATHER, J. H., Lancet, 1939, 2, 183. 